\title{
A Review on RF Field Exposure from Cellular Base Stations
}

\author{
Amar Renke \\ Department of Electronics Engineering \\ KIT's College of Engineering, \\ Kolhapur, India
}

\author{
Mahesh Chavan \\ Department of Electronics Engineering \\ KIT's College of Engineering, \\ Kolhapur, India
}

\begin{abstract}
This review paper, takes into account previously published papers based on human exposure to electromagnetic fields which is radiated from cellular base stations and its corresponding adverse effects on human beings. This paper reviews the estimation and evaluation of the human exposure to electromagnetic fields (EMF); these radiated fields from cellular base stations which aim to verify the exposure compliance with human protection guidelines. There is an abundant literature in which experiments are carried out to study what effects the radiated fields have when human cells are exposed to such exposure. Here exposure situation considered is around the base stations and the approximate distance from base station is from $5 \mathrm{~m}$ to $150 \mathrm{~m}$. Different exposure measurement methods were used in different papers such as single point measurement method or spatial averaging methods, such as $3,6,9,20$ points. Selected countries in Europe and elsewhere has taken the EMF exposure survey and compared the results with guidelines developed by the International Commission on Non-Ionizing Radiation Protection (ICNIRP). The paper also focuses on different international standards developed for EMF exposure from base stations. Finally adverse biological effects of EMF exposure from various papers are summarized.
\end{abstract}

\section{General Terms}

Electromagnetic field exposure, Ionizing and Non-Ionizing radiations, cellular base stations.

\section{Keywords}

Radio frequency, electromagnetic field, human exposure guidelines, EM radiation, Uncertainty, public concern, Perceptions, In situ, mobile switching center (MSC), Biological effect.

\section{INTRODUCTION}

The fast changing world of mobile telecommunications has raised concern amongst many local communities over possible health effects from exposure to electromagnetic radiation, which is radiated from cellular base stations. Therefore the communities situated in the vicinity of base stations are now asking questions today, regarding what is the EMF exposure level that is radiated from cellular base stations? Whether it is below the standard level defined by ICNIRP or not? And what are its adverse effects on creatures. This paper will try to answer these questions; the next section will give the basic back ground of electromagnetic radiation, basic concepts and electromagnetic spectrum

\subsection{Basic concepts in Electromagnetics}

The range of frequencies comes in the band $3 \mathrm{kHz}$ to $300 \mathrm{GHz}$ are called as radio frequencies. These frequencies are used in various applications such as radio broadcasting, television broadcasting and cellular mobile communication. These applications require radio waves. A radio wave propagated by an antenna in free space is called as EM wave. These waves have diverse Energy levels transmitted from a source is generally known as EM radiation. The various Examples of EM radiation waves are from radio and Television broadcast transmitters, microwave transmitters and mobile base station towers.

\subsection{Electromagnetic Spectrum}

Universally accepted system to get solutions for connectivity in point-to-point and point-to multipoint applications is Cellular communication system. The examples of wireless communications are $\mathrm{AM}$ and $\mathrm{FM}$ radio, television broadcasting, cellular phones, radar and microwave systems etc. The electromagnetic (EM) frequency spectrum consists of two main categories ionizing and non ionizing radiation.

Figure 1.0 shows a graphical representation of the spectrum of EM energy or radiation. Each frequency range has its corresponding application area shown in figure 1.0. There are two types of EM radiations one is ionizing and second is nonionizing radiation.

The radiation from cellular base stations comes under nonionizing radiation and frequencies used are 900, 1800, 1900 and $2100 \mathrm{MHz}$. Ionizing radiation affects the human organs in greater extent. The cellular base stations which radiates the Non-ionizing radiation does not alter the atomic structure of creatures, but still affects the human cells in manners which is not fully understood yet, may create negative human health effects. The EM radiation from cellular base stations is of Nonionizing radiation.

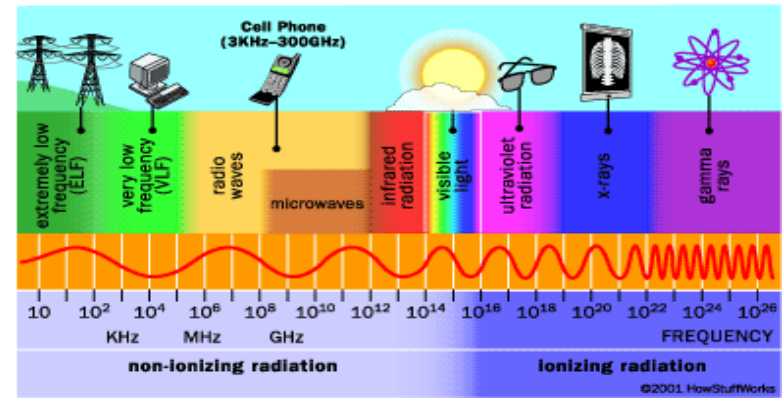

Figure 1.0 Electromagnetic spectrum (open source image).

\subsection{Cellular Communication}

Today CDMA and W-CDMA technology is widely used for cellular communication, for which the total geographical area covered by cellular mobile systems is divided into small geographic areas known as cells. Every cell consisting of a base station that communicates with mobiles subscribers in the cell by transmitting and receiving signals on RF links. Two main links are used for communication purpose from 
mobile to base station and vice-versa. Each base station is linked with a mobile switching center (MSC) that connects calls to and from the base station to mobiles in other cells and the public switched telephone network.

\subsection{RF Exposure Concerns}

The worldwide use of mobile telephony has increased considerably with the introduction of the digital technologies such as GSM 900 / DCS 1800 in 1990s. Today 80\% of the population of the world is using mobile telephones in urban environment. This increased use of mobile phones has led to an important deployment of base stations. The increased number of base stations in a country depends on several factors such as the number of network providers, number of users, number of simultaneous calls etc. Such base stations are often situated close to dwellings or houses and become the cause for concerns of human exposure in the recent years.

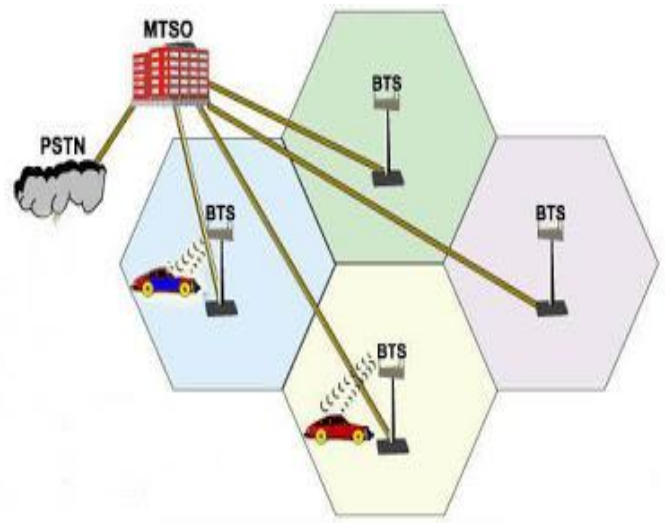

Figure 2.0 Cellular mobile communications (open source image)

Therefore this population desires to know the level of radio frequency (RF) electromagnetic field (EMF) exposure due to the base stations. Whether these radiation levels of exposure are health related? Whether they follow national and international standards, guidelines, regulations or similar rules and regulations? [1]-[5]. To answer these questions local and national authorities or agencies, network providers and private persons, experienced institutions to investigate the RF electromagnetic field exposure levels in restricted areas. Public concern being high in countries like France, Romania Italy, Australia [20], New Zealand [11], Lisbon, and Korea.

In addition to the theory, in 2000 Paolo Bernardi and Matra Cavagnaro presented results of the human exposure to the electromagnetic field radiated by a radio base-station antenna operating around $900 \mathrm{MHz}$ [9]. In 2005, Emmanuel Larcheveque and Christian Dale present result of the analysis of electric field averaging for in situ RF exposure assessment [17]. S I Henderson and M J Bangay completed survey on RF exposure levels from mobile telephone base stations in Australia in 2006.

To evaluate the possible impact of exposure to electromagnetic radiation from mobile communications, studies have been carried out in the area of exposure field measurement [4] - [8] and possible consequences of human exposure to such fields. In spite of the effort of scientific community, little is known about general public exposure from mobile communication systems and contribution of different types of services [6], [7], [10].

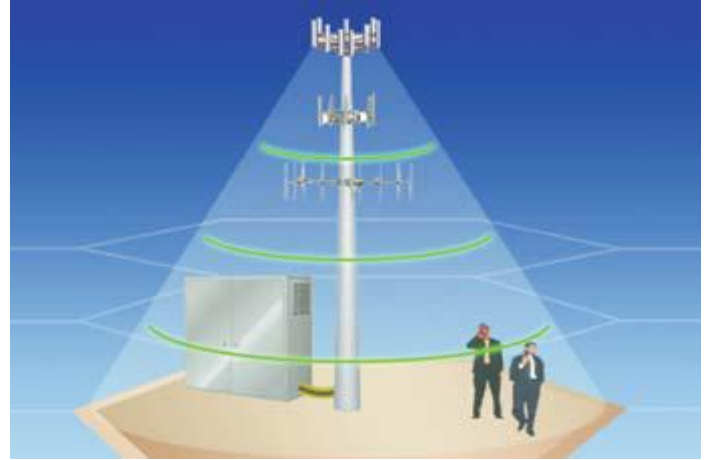

Figure 3.0 Human Exposures to EMF (open source image)

Different counties have taken the review of electromagnetic field exposure from base stations and concluded that in some cases electromagnetic field.

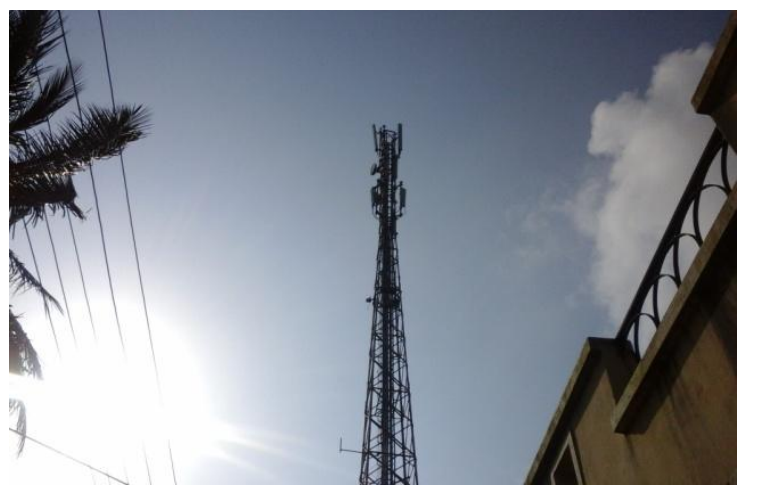

Figure 4.0 Cellular base station sites

Exposure is high and in some it is well below standard reference level [17],[20],[24]. Figure 3.0 shows the human exposure to RF electromagnetic field and figure 4.0 different base station sites.

This paper reviews the previously published work which has been carried out regarding the measurement and estimation of $\mathrm{RF}$ electromagnetic (EM) field strength related to human exposure from cellular base stations and possible health effects of RF exposure [8]. The next session presents the survey of different EMF exposure methods. First an introduction to international rules and regulations to EMF exposure levels is given. Then different approaches of EMF exposure from different papers are presented. The frequencies of interest are from $3 \mathrm{KHz}$ to $300 \mathrm{GHz}$.

\section{MATERIALS AND METHODS}

The purpose of computing the EMF exposure is to protect the people from excessive EM radiation from base stations, and from its adverse health effects.

\subsection{EMF Exposure standards and guidelines}

In 1974, the international radiation protection association (IRPA) created a working group on non-ionizing radiation (NIR), which examined the problems arising in the field of protection against the various types of NIR [6]. This working group became the International Non-Ionizing Radiation Committee (INIRC). At the international congress of the IRPA a new independent scientific organization - the international Commission on non-ionizing radiation Protection (ICNIRP) - was established as a success to the IRPA/INIRC. The main objective of ICNIRP was to establish 
guidelines for limiting EMF exposure that will make available protection against known adverse health effects. This effects cause's measurable impairment of the health of the exposed individual, a biological effect. Studies on both direct and indirect effects of EMF are preferred; direct effect produced from direct interaction of fields with the body; indirect effects engage interactions with an object at a different electric potential from the body. ICNIRP guidelines cover the whole frequency range of time varying EMF (up to $300 \mathrm{GHz}$ ) and published in 1998. In establishing exposure limits, the commission recognizes the want to reconcile a number of different opinions. The soundness of scientific reports has to be considerably and extrapolations from animal experiments to effects on humans have to be made. The limitations in these guidelines were based on scientific data alone, presently available knowledge, these restrictions provides adequate level of protection from exposure to time-varying EMF. Two classes of guidelines are presented.

Basic restrictions - To avoid the adverse health effects on leaving things keep the EM radiation exposure levels within limits are termed as "basic restrictions"

Reference levels - These levels are provided for practical exposure evaluation purposes to determine whether the basic restrictions are likely to be exceeded.

Table 1.0 International Radiation Density Limits adopted by different countries

\begin{tabular}{|c|c|}
\hline $\begin{array}{l}\text { Power } \\
\text { Density } \\
\left(\mathbf{W} / \mathbf{m}^{2}\right)\end{array}$ & $\begin{array}{c}\text { International Exposure limits adopted by } \\
\text { various countries }\end{array}$ \\
\hline 10 & $\begin{array}{l}\text { FCC (USA) Public Exposure Guidelines at } 1800 \\
\qquad \mathrm{MHz}\end{array}$ \\
\hline 9.2 & $\begin{array}{l}\text { ICNIRP and EU recommendation } 1998 \text { - Adopted } \\
\text { in India }\end{array}$ \\
\hline 3 & Canada \\
\hline 2 & Australia \\
\hline 1.2 & Belgium \\
\hline 0.5 & New Zealand \\
\hline 0.24 & Exposure limit in CSSR, Belgium, Luxembourg \\
\hline 0.1 & Exposure limit in Poland, China, Italy, Paris \\
\hline 0.095 & $\begin{array}{c}\text { Exposure limit in Italy in areas with duration > } \\
\text { 4hours }\end{array}$ \\
\hline 0.095 & Exposure limit in Switzerland \\
\hline 0.09 & (Germany) Precaution recommendation only \\
\hline 0.025 & Exposure limit in Italy in sensitive areas \\
\hline 0.02 & Exposure limit in Russia, Bulgaria, Hungary \\
\hline 0.001 & $\begin{array}{c}\text { "Precautionary limit" in Austria, Salzburg City } \\
\text { only }\end{array}$ \\
\hline 0.0009 & BUND 1997 (Germany) \\
\hline 0.00001 & New South Wales, Australia \\
\hline
\end{tabular}

In July 1999, European community established guidelines for limitation of exposure of general public to electromagnetic fields [7]. Some of the important guidelines are
To protect general public against adverse health effects of exposure to electromagnetic fields

Electromagnetic fields should give all community citizens a high level of protection.

Actions on limiting the exposure of general public to electromagnetic field should be balanced with the other health, safety and security benefits that devices emitting electromagnetic fields bring to quality of life.

After studying the ICNIRP guidelines and European community recommendations on human exposure related to electromagnetic fields in 1998 . The table 1.0 shows different standards for electromagnetic field exposure.

Then Ronold W P King presented how electromagnetic fields exposure affects the nerves in a human body in 1999[8]. Currents and electric fields stimulate in the organs of the human body by external electric and magnetic fields are introduced. The electric currents and fields generated in the human body when this is exposed to the electromagnetic fields generated by 50 or $60 \mathrm{~Hz}$ high voltage transmission lines or 10 $40 \mathrm{KHz}$ transmitter. The normal functions of living cells in the tissues of the human body involve electric charges and currents and the electric fields generated by them. Since exposure to externally electromagnetic fields leads to induced electric currents and fields in all organs and cells of the body, the effects of superimposed these on those that are part of the living process is of main scientific interest. It is shown that exposure of human body to the $60 \mathrm{~Hz}$ electric field of high voltage transmission line of the order of $1800 \mathrm{v} / \mathrm{m}$ or $2000 \mathrm{v} / \mathrm{m}$ involves no interference with normal functioning of a nerve.

In 2000, a hybrid ray tracing/finite difference time -domain (FDTD) method has been used to estimate the incident field and the power absorbed in an exposed subject in the presence of reflecting walls. The base station antenna has been exemplified by means of its radiation pattern, evaluated with FDTD analysis. All the checked cases, the obtained results, in terms of incident field and absorbed power, are below the safety standard levels.

The ICNIRP 1998 guidelines are modified in 2001 by Australian radiation protection and nuclear safety agency (ARPANSA) and the Australian communications authority (ACA)[10]. A working group was established by ARPANSA's Radiation Health committee (RHC) to outline a set of maximum exposure levels for RF fields in the frequency range $3 \mathrm{KHz}$ to $300 \mathrm{GHz}$. The working group studied the scientific literature extensively. The proposed standard applies wherever and whenever occupational groups and the general public may be exposed to RF fields in the frequency range $3 \mathrm{KHz}$ to $300 \mathrm{GHz}$ range.

After studying the ICNIRP guidelines and European community recommends on human exposure related to electromagnetic fields in 1998.

The Greek Atomic Energy Commission (EEAE) in 2002 carries out measurements in the vicinity of all kinds of facilities emitting RF electromagnetic fields, in order to examine whether the general public exposure limits are being adhered to [12]. The evaluation of uncertainty in the measurements is carried out and is crucial in the cases where measured values are close to the safety limits.

In 2003, Electronic Communications Committee (ECC) recommends in situ measurement procedures in order to assess electromagnetic fields for the purpose of comparison in opposition to limits for human exposure applying in CEPT 
countries [14]. This recommendation does not itself standardize. This recommendation should be reviewed every three years. This review should take into account all information coming from any pertinent groups within CEPT, CENELEC, and IEC/ICES. This recommendation will help other competent bodies in their work and interchange of information.

James C Lin in 2003, published article on safety standards for human exposure to radio frequency and their biological rationale. Currently people are not much aware of RF exposure standards in developing countries, they are not confident about radio frequency exposure standards, pertaining to the utmost permissible exposure (MPE) level of humans exposed to RF EM radiation. However understanding of biological effects of exposure to RF radiation is still developing and more so for cellular mobile telephones. It is expected and mandatory that human exposure guidelines should be time to time updated. Likewise, rationales for the exposure criteria must be re-examined in view of laboratory finding and human health studies.

In 2003, G Neubauer, W Giczi and G Schmid gave analysis of exposure levels next to GSM base stations. To measure the exposure levels they uses two methods spot measurements and evaluation of worst case exposure to single base stations [15].

General public exposure around GSM and UTMS cellular base stations was carried out by $\mathrm{Chr}$ bornlessel and $\mathrm{M}$ Schubert in 2003[63]. This paper presents two approaches. One is measurement and calculation of EM radiation of spectrum analyzer. In second approach several commercially available simulation tools for exposure predication are experienced. Different methods are tested here for exposure measurement such as deviations in space and time, space maximization, time maximization and space and time averaged measurements. For measurements especially those sites were preferred, which had GSM and UTMS system. 85 $\%$ of all measurement points show that GSM exposure was higher than UTMS exposure. Finally the software packages were useful to several real scenarios and the results compared to actual measurements.

T G Cooper, S M Mann, K Khalid and R P Blackwell [16] has been assessed Exposures of the general public to radio waves emitted by microcell and pico-cell base stations for mobile telecommunications through theoretical and experimental means in 2004. Generally, exposures to radio waves transmitted over a range of frequencies in the VHF and UHF bands by a variety of sources have also been examined experimentally. Twenty GSM base stations were selected at random from a group of 3000 that had small antenna height and little radiated power, in accordance with accepted characteristics of micro-cell and Pico-cell base stations.

Christian Dale published analysis of electric field averaging for In Situ radio frequency exposure assessment in July 2005[17]. Here the impact of small scale fading on the assessment of local average power density for radio frequency exposure assessment is studied in the case of a Rayleigh fading, a Rician-k fading, and a Nakagami-m fading.

In all cases it is shown that the major parameter is the coefficient of variation of power density. Moreover, measurements can be performed to get some arithmetical information about fading severity in real environments.

Christof Oliveier and Luc Martens [18] presented some issues in 2005, regarding narrow band measurements of digital modulated communication signals are discussed within the context of compliance verification of base stations to the exposure limits. When frequency selective measurements are exposed to find out the worst-case exposure to electromagnetic fields around a base station, the spectrum analyzer settings should be chosen correctly to obtain valid measurement results.

As mentioned in a fact sheet published in 2006, number of base stations and wireless networks increasing, this increases the RF exposure [19]. fresh surveys have shown that the RF exposures from base stations range from $0.002 \%$ to $2 \%$ of the levels of international exposure guidelines. In the fact sheet different health concerns are talked about such as cancer and other effects. Considering the very low exposure levels and research results composed to date, there is no convincing scientific proof that the weak RF signals from base stations and wireless networks cause adverse health effects.

An Australian survey conducted by S I Henderson and M J Bangay [20] gives the results of an RF exposure levels from mobile telephone base station antennas in 2006. Measurements of CDMA800, GSM900, GSM1800, and 3G (UMTS) signals were performed at distances ranging over 50 to $500 \mathrm{~m}$ from approximately 60 base stations in five Australian cities. The exposure levels from these cellular base stations were found to be well under the general public exposure limits of the ICNIRP guidelines and the Australian radiofrequency standard (ARPANSA RPS3). The peak recorded level from a solitary base station was $7.8 \times 10^{-3}$ $\mathrm{W} / \mathrm{m} 2$, which translates to $0.2 \%$ of the general public exposure limit.

In June 2006, European standard was prepared for electromagnetic fields in the human environment by technical committee CENELEC. The standard is published as "basic standard to demonstrate the compliance of fixed equipment for radio transmission $(110 \mathrm{MHz}-40 \mathrm{GHz})$ intended for use in wireless telecommunication networks with the basic restrictions or the reference levels related to general public exposure to radio frequency electromagnetic field, when put into service [21]."

A review paper is published by $\mathrm{J}$ Kilma and R Scehovic in 2006 on "Field strength measurement and SAR experience related to human exposure in $110 \mathrm{MHz}$ to $40 \mathrm{GHz}$." The paper investigates the characteristics radiation of lower $(110 \mathrm{MHz}$ to $2 \mathrm{GHz}$ ) and higher $(2 \mathrm{GHz}$ to $40 \mathrm{GHz}$ ) frequency bands. A European norm EN 50383 basic standards for calculation and measurement of electromagnetic field strength and SAR connected to human exposure from base station is used. Measurements are performed according to suitable proclamation No 271/2004 of the ministry of health of Slovak republic. The local SAR measurement is based on fathom model, which simulate the human body exposure by electromagnetic field radiated from antenna.

The monIT project published in 2007 provides public information on population exposure to EMF from mobile communication systems in Portugal. The monitoring system is supported on a $\mathrm{n} / \mathrm{w}$ of autonomous remote probing stations and also on an extensive EMF sounding program, both carried out in public areas in the whole country. Measured results are automatically uploaded to a web site for public broadcasting [2007].

Kim B C written an article in 2008on measurement methods used to determine the human exposure to electromagnetic fields radiated from operating base stations. In Korea, when 
assessing the human exposure to electromagnetic fields from operating base stations [2008], two approaches are explained i.e. In situ measurement and electromagnetic environment measurement. When performing situ measurement, obedience with human exposure limits are determined by the spatially averaged field value obtained within the space occupied by humans at one random position, but when performing an electromagnetic environment measurement, it is calculated by the utmost value at the highest field position selected from several places.

EN 50492 is the "basic standard for the in-situ measurement of electromagnetic field strength related to human exposure in the vicinity of base stations" is the European standard approved by CENELEC in November 2008. This European standard is useful when measurement is done at a particular place [5]

In 2010, Denial Sebastian from technical university of Lisbon aspire at estimation of exclusion zones around typical installations of base station antennas, which characterized areas within which electromagnetic fields exposure guidelines are exceeded, in order to protect general public from potential harmful levels of radiation. A classification of different types of base station antennas setting up is presented. Essential parameters for the estimation of the exclusion zone are also recognized. Exclusion zones are may be obtained either by measurements or by prediction [2010].

A survey on "residential exposure to radiofrequency fields from mobile phone base stations, and broadcast transmitters" was conducted by J V Viel and S Clerc. A total of 200 randomly selected people were registered. Each participant was supplied with a personal exposure meter for 24 hours measurement, and kept a time location-activity diary.

In Romania, investigation on residential exposure to EM radiation in the proximity of mobile phone base stations is carried out by C Goiceance and R Dannlescu in 2010. Here unlike exposure situations were taken into account concerning the location of measurement points in relation to antenna and propagation conditions. To evaluate the worst case residential exposure, they measured EMF levels in different locations of the houses such as room, balcony, loggia and roof-terrace. Measured EMF levels ranged between $0.25-9.7 \mathrm{v} / \mathrm{m}$. The major contributor to the total amount of exposure to EMF in dwellings is from mobile phone base stations.

In 2012, Byung Chan Kim, Jae-Hoon Yun, and Seong-Ook Park investigates the estimation of uncertainty when evaluating the levels of human exposure to electromagnetic fields radiated from cellular base stations which aim to verify the exposure compliance with human protection guidelines. Here first time concept of uncertainty is introduced in measuring RF exposure levels.

The concept of Uncertainty should be used when publishing the results of an evaluation since measured physical quantities are not complete unless they are accompanied by some indication of their reliability. In this study, uncertainty sources are divided into four groups: physical parameters, mechanical constraints, post processing, and measurement equipment. Type A standard uncertainties are obtained from repetitive observations by in situ measurement around cellular base stations, and they comprise uncertainties introduced by sources other than measurement equipment. Type B uncertainties are calculated from the calibration data of the measuring equipment. The estimated total uncertainty is $\pm 3.82 \mathrm{~dB}$.
In this way review of various methods of RF EMF exposure from base stations have been taken since 1974. Countries like United States, Australia, New Zealand, France, and Korea had taken the survey of EMF exposure levels and result Shows exposure levels in some cases is within the limit and in some cases it is Exceeding the limits. In some papers exposure levels are calculated in terms of standard uncertainty.

\section{CONCLUSION}

Previous papers concerning the human exposure levels to RF electromagnetic fields from cellular base stations have been reviewed. Different methods of human exposure levels to RF electromagnetic fields have been presented by different countries. The results shows that human exposure levels to RF electromagnetic fields from base stations are within the limit in some cases. But in other cases it is varying and people in nearby base station area get affected due to high RF electromagnetic field exposure levels.

Since 1974 different methods are reviewed some methods calculated human exposure levels in residential areas, inside the dwellings such as room, balcony, loggia and roof-terrace etc. other methods estimated exposure levels in the vicinity of base stations. The adverse biological effects are also studied in some papers i.e. how RF EM radiation affects the human nerve system. No much focus is given on how RF EM radiation from base station affects the birds and animals. Today therefore it is necessary to control EM radiation from cellular base stations to protect the creatures. This type of work is not focused in our country yet.

\section{ACKNOWLEDGEMENT}

The author would like to sincerely thank to department of technology, Shivaji University and KIT's college of engineering, Kolhapur for providing the facilities.

\section{REFERENCES}

[1] Byung Chan Kim, Jae-Hoon Yun, And Seong-Ook Park, Member, Ieee "Uncertainty Estimation For Evaluating Human Exposure Levels To Rf Electromagnetic Fields From Cellular Base Stations" Ieee Transactions On Electromagnetic Compatibility, Vol. 54, No. 2, April 2012

[2] Icnirp, "Guidelines For Limiting Exposure To Time Varying Electric, Magnetic, And Electromagnetic Field (Up To 300 Ghz)," Health Phys., Vol. 74, No. 4, Pp. 494-522, 1998.

[3] Radiation Protection Standard "Maximum Exposure Levels To Radiofrequency Fields - 3 Khz To 300 Ghz" Radiation Protection Series Publication No. 3 Arpansa.

[4] Cenelec Standard En 50383, "Basic Standard For Calculation And Measurement Of Electromagnetic Field Strength And Sar Related To Human Exposure From Radio Base Stations And Fixed Terminal Stations For Wireless Telecommunications System" (110 Mhz - 40 Ghz), Cenelec Standard En 50383, 2002.

[5] Cenelec Standard En50420, "Basic Standard For The Evaluation Of Human Exposure To Electromagnetic Fields From Stand Alone Broadcast Transmitter" (30 Mhz-40 Ghz), Cenelec Standard En50420, 2006.

[6] Cenelec Standard, En50492, "Basic Standard For In-Situ Measurement Of Electromagnetic Field Strength Related To Human Exposure In The Vicinity Of Base Stations", Cenelec Standard, En50492, 2008. 
[7] Cenelec Standard En50400, "Basic Standard To Demonstrate The Compliance Of Fixed Equipment For Radio Transmission (110 Mhz - $40 \mathrm{Ghz})$ Intended For Use In Wireless Telecommunication Networks With The Basic Restrictions Or The Reference Levels Related To General Public Exposure To Radio Frequency Electromagnetic Fields, When Put Into Service, Cenelec Standard En50400, 2004.

[8] B. C. Kim, H. -D. Choi And S.-O. Park, "Methods Of Evaluating Human Exposure To Electromagnetic Fields Radiated From Operating Base Stations In Korea, " Bio- Electromagnetics, Vol. 29, No. 7, Pp. 579- 582, Oct. 2008.

[9] B. C. Kim, And S.- O. Park, "Reduction Of Averaging Time For Evaluation Of Human Exposure To Radio Frequency Electromagnetic Fields From Cellular Base Stations," Ieice Tran. Communication, Vol.B, No. 7, Pp.1862-1864, Jul. 2010.

[10] E. Larch^Eveque, C. Dale, M. Wong, And J. Wiart, "Analysis Of Electric Field Averaging For In-Situ Radio Frequency Exposure Assessment," Ieee Trans. Veh. Technol.,Vol. 54, No. 4, Pp. 1240-1250, Jul. 2005.

[11] S. Kuhn And N. Kuster, "Evaluation Of Measurement Techniquestoshowcompliance With Rf Safety Limits In Heterogeneous Field Distributions," Ieee Trans. Electromagn. Compat., Vol. 52, No. 4, Pp. 820-828, Nov. 2010.

[12] W. C. Y. Lee, "Estimate Of Local Average Power Of A Mobile Radio Signal," Ieee Trans. Veh. Technol., Vol. 34, No. 1, Pp. 22-27, Feb. 1985.

[13] Cenelec En50166, "Human Exposure To Electromagnetic Fields.High Frequency" (10 Khz To $300 \mathrm{Ghz}$ ), Cenelec En 50166-2, Jan. 1995.

[14] S. I. Henderson And M. J. Bangay, "Survey Of Rf Exposure Levels From Mobile Telephone Base Stations In Australia," Bioelectromagnetics, Vol. 27, Pp. 73- 76, 2006.

[15] D. Molkdar "Review On Radio Propagation Into And Within Buildings" Iee Proceedings-H, Vol. 138, No. I , February 1991

[16] Bernard H. Fleury, Swiss Federal Institute Of Technology, Zurich Peter E. Leuthold, Swiss Federal Institute Of Technology, "Radio Wave Propagation In Mobile Communications: An Overview Of European Research", Zurich Ieee Communications Magazine 0 February 1996

[17] Chr. Bornkessel1, M. Schubert, M. Wuschek, P. Schmidt "Measurement And Calculation Of General Public Electromagnetic Exposure Around Gsm And Umts Cellular Base Stations"

[18] Goiceanu, R. Danulescu, E. Danulescu "Investigation On Residential Exposure To Electromagnetic Radiation In The Proximity Of Mobile Phone Base Stations". Cproceedings of The 40th European Microwave Conference, 28-30 September 2010, Paris, France

[19] Paolo Bernardi, Life Fellow, Ieee, Marta Cavagnaro, Member, Ieee, Renato Cicchetti, Senior Member, Ieee, Stefano Pisa, Member, Ieee, Emanuele Piuzzi, And Orlandino Testa "A Utd/Fdtd Investigation On Procedures To Assess Compliance Of Cellular Base-
Station Antennas With Human-Exposure Limits In A Realistic Urban Environment Ieee Transactions On Microwave Theory And Techniques, Vol. 51, No. 12, December 2003

[20] Carla Oliveira1, Daniel Sebastijo1, Gongalo Carpinteirol, Luis M. Correia', Carlos A. Fernandes1, Afonso Serralha2, And Nuno Marques2 "The Monit Project: Electromagnetic Radiation Exposure Assessment In Mobile Communications" Ieee Antennas And Propagation Magazine, Vol. 49, No. 1, February 2007

[21] Fellow, Ieee, Marta Cavagnaro, Stefano Pisa, Member Paolo Bernardi, Ieee, And Emanuele Piuzzi, "Human Exposure To Radio Base-Station Antennas In Urban Environment" Ieee Transactions On Microwave T Heory And Techniques, Vol. 48, No. 11, November 2000

[22] E. Karabetsos, G. Filippopoulos Non Ionizing Radiation Office, "Uncertainty Estimation In Electromagnetic Field Measurements For Assessing Compliance With Safety Limits" Greek Atomic Energy Commission P.O. Box: 60092, Zip Code 15310, Ag.Paraskevi Attikis, Greece

[23] Latin American Experts Committee On High Frequency Electromagnetic Fields And Human Health Scientific Review Non-Ionizing Electromagnetic Radiation In The Radiofrequency Spectrum And Its Effects On Human Health With A Review On The Standards And Policies Of Radiofrequency Radiation Protection In Latin America June 2010.

[24] D. D. Wackerly, W. Mendenhall Iii, And R. L. Scheaffer, Mathematical Statistics With Applications, 7th Ed. Duxbury, Ma: Thomson, 2008, Pp. 839-849.

[25] "Nerves In A Human Body Exposed To Low-Frequency Electromagnetic Fields" Ronold W. P. King, Life Fellow, Ieee Ieee Transactions On Biomedical Engineering, Vol. 46, No. 12, December 1999

[26] Oriano Bottauscio, Mario Chiampi, And Luca Zilberti , "Boundary Element Approaches For The Evaluation Of Human Exposure To Low Frequency Electromagnetic Fields" Ieee Transactions On Magnetics, Vol. 45, No. 3, March 2009

[27] Markus Clemens, Stefan Dickmann, Abdessamad El Ouardi, Volkert Hansen, Martin Schaarschmidt, Joachim Streckert, And Yi Zho "Numerical Dosimetry Schemes For The Simulation Of Human Exposure To Pulsed High-Power Electromagnetic-Field Sources"

[28] James C. Lin "Safety Standards For Human Exposure To Radio Frequency Radiation And Their Biological Rationale" Ieee Microwave Magazine December 2003

[29] Marie-Christine Gosselin, G“Unter Vermeeren, Sven K"Uhn, Valpr'E Kellerman, Stefan Benkler "Estimation Formulas For The Specific Absorption Rate In Humans Exposed To Base-Station Antennas", Ieee Transactions On Electromagnetic Compatibility, Vol. 53, No. 4, November 2011

[30] Dr Duncan Fung, "Fundamentals And Regulations Of Human Safety Concerns For Mobile Communications Devices" Consultant Hong Kong Productivity Council

[31] Rj. Douglas1 And C. Thomas On Behalf Of The Working Group Members, "29th Annual Precise Time And Time Interval (Ptti) Meeting "The Cctf Working 
Group On The Expression Of Uncertainties In Primary Frequency Standards"

[32] James C. Lin, "Perspectives On Guidelines For Herman Exposure To Radio-Frequency Radiation" Ieee Antennas Arid Propagation Magazine, Vol. 42, No. 1, February 2000

[33] Barry N. Taylor And Chris E. Kuyatt, "Guidelines For Evaluating And Expressing The Uncertainty Of Nist Measurement Results", Nist Technical Note 12971994 Edition

[34] Daniel Sebastião, Diana Ladeira, Mónica Antunes, Carla Oliveira, Luís M. Correia, "Estimation Of Base Stations Exclusion Zones" Instituto De Telecomunicações / Instituto Superior Técnico Technical University Of Lisbon Lisbon, Portugal

[35] Advice On Limiting Exposure Electromagnetic Fields 0300ghz Nrpb National Radiological Protection Board

[36] T G Cooper, S M Mann, M Khalid And R P Blackwell, "Exposure Of The General Public To Radio Waves Near Microcell And Picocell Base Stations For Mobile Telecommunications Final Report" Nrpb, Chilton, Didcot, Ox11 0rq

[37] Radio Communications (Electromagnetic Radiation Human Exposure) Standard 2001

[38] Emf Exposure Standards In New Zealand Martin Gledhill National Radiation Laboratory, P O Box 25099 , Christchurch, New Zealand

[39] G. Neubauer, W. Giczi, G. Schmid, Analysis Of Exposure Levels Next To Gsm Base Stations.

[40] Williaii C. Y. Lee, "Theory Of Wideband Radio Propagation" Ch2944-7/91/0000/0285 \$1 .Oo 81991 Ieee

[41] Power-Frequency Emf Exposure Standards Applicable In Europe And Elsewhere Compiled By John Swanson October 2012

[42] Ordinance Of Protection Against Non-Ionizing Radiation (Nisv) $\quad 23^{\text {rd }}$ December 1999

[43] Ieee Standard For Safety Levels With Respect To Human Exposure To Radio Frequency Electromagnetic Fields 1999

[44] J F Viel, S Clerc, C Barrera, R Rymzhanova, M Moissonnier, M Hours, E Cardis, "Residential Exposure To Radiofrequency Fields From Mobile Phone Base Stations, And Broadcast Transmitters: A PopulationBased Survey With Personal Meter" Occup Environ Med 2009;66:550-556. Doi:10.1136/Oem.2008.044180 December 3, 2012

[45] Kjell Hansson Mild, "Exposure Of Workers To Electromagnetic Fields. A Review Of Open Questions On Exposure Assessment Techniques" International Journal Of Occupational Safety And Ergonomics (Jose) 2009, Vol. 15, No. 1, 3-33

[46] Wout Joseph, Christof Olivier, And Luc Martens "A Robust, Fast, And Accurate Deconvolution Algorithm For Em-Field Measurements Around Gsm And Umts Base Stations With A Spectrum Analyzer" Ieee Transactions On Instrumentation And Measurement, Vol. 51, No. 6, December 2002
[47] "Optimal Settings For Narrow-Band Signal Measurements Used For Exposure Assessment Around Gsm Base Stations" Christof Olivier And Luc Martens, Member, Ieee Transactions On Instrumentation And Measurement, Vol. 54, No. 1, February 2005

[48] Emmanuel Larch^Eveque, Christian Dale, Man-Fa“I Wong, Senior Member, Ieee, And Joe Wiart, Senior Member, "Analysis Of Electric Field Averaging For In Situ Radiofrequency Exposure Assessment" Ieee Transactions On Vehicular Technology, Vol. 54, No. 4, July 2005

[49] "Development Of Procedures For The Emf Exposure Evaluation Of Wireless Devices In Home And Office Environments Exposure From Wireless Data Communication Devices" - Final Report, Zurich, July, 2006

[50] W Raeyoung Jr "Comparison Of Mobile Radio Transmission At 150, 450, 900, And 3700 Mc.” The Bell System Technical Journal. November 1952.

[51] W C Y Lee, "Estimate Of Local Average Power Of A Mobile Radio Signal", Ieee Transactions On Vehicular Technology, Vol. Vt-34, No. 1, February 1985

[52] Marie-Christine Gosselin, G“Unter Vermeeren, Sven K"Uhn, Valpr'E Kellerman, Stefan Benkler, "Estimation Formulas For The Specific Absorption Rate In Humans Exposed To Base-Station Antennas", Ieee Transactions On Electromagnetic Compatibility, Vol. 53, No. 4, November 2011

[53] Sven K"Uhn And Niels Kuster, "Evaluation Of Measurement Techniques To Show Compliance With Rf Safety Limits In Heterogeneous Field Distributions" Ieee Transactions On Electromagnetic Compatibility, Vol. 52, No. 4, November 2010

[54] Oriano Bottauscio, Mario Chiampi, And Luca Zilberti , "Boundary Element Approaches For The Evaluation Of Human Exposure To Low Frequency Electromagnetic Fields", Ieee Transactions On Magnetics, Vol. 45, No. 3, March 2009.

[55] Franco Pavese "Analysis Of Consistency Of The Concepts For The Expression Of Uncertainty In The Present International Written Standards And Guidelines, $16^{\text {th }}$ Imeko Tc\$ Symposium, Italy.

[56] E. Karabetsos, G. Filippopoulos "Uncertainty Estimation In Electromagnetic Field Measurements For Assessing Compliance With Safety Limits" Non Ionizing Radiation Office, Greek Atomic Energy Commission

[57] Wout Joseph, Christof Olivier, And Luc Martens, "A Robust, Fast, And Accurate Deconvolution Algorithm For Em-Field Measurements Around Gsm And Umts Base Stations With A Spectrum Analyzer", Ieee Transactions On Instrumentation And Measurement, Vol. 51, No. 6, December 2002

[58] Ryser H. "Measuring Campaign For The Assessment Of The Non-Ionising Radiation Near Gsm Base Stations". 15th Intl. Symposium And Technical Exhibition On Emc Zurich, Pp. 171-174, 2003

[59] M. Siegrist, T. C. Earle, H. Gutscher, C. Keller, "Perception Of Mobile Phone And Base Station Risks"., Risk Anal., Vol. 25, Pp. 1253-1264, Oct. 2005. 
[60] Fusette, G. D'amore, "Population Exposure To Electromagnetic Fields Generated By Radio Base Stations: Evaluation Of The Urban Background By Using Provisional Model And Instrumental Measurements"., Radiat. Prot. Dosimetry, Vol. 97, Pp. 355-358 Dec. 2001.

[61] J.F. Viel, E. Cardis, M. Moissonnier, R. De Seze, M. Hours, "Radiofrequency Exposure In The French General Population: Band, Time, Location And Activity Variability”., Environ. Int., Vol. 35, Pp. 1150-1154, Nov. 2009.

[62] J. Vanderstraeten, "Gsm Fields And Health: An Updated Literature Review"., Rev. Med. Brux, Vol. 30, Pp. 416424, Sep. 2009. (In French)

[63] R. Santini, P. Santini, J.M. Danze, P. Le Ruz, M. Seigne, ."Investigation On The Health Of People Living Near Mobile Telephone Relay Stations: I/Incidence According To Distance"., Pathol. Biol. (Paris), Vol. 50, Pp. 369373, Jul. 2002. (In French).

[64] R. Santini, P. Santini, J.M. Danze, P. Le Ruz, M. Seigne, ."Symptoms Experienced By People In Vicinity Of Base Stations: Ii/ Incidences Of Age, Duration Of Exposure, Location Of Subjects In Relation To The Antennas And Other Electromagnetic Factors"., Pathol. Biol. (Paris), Vol. 51, Pp. 412-415, Sep. 2003. (In French).

[65] P. A. Valberg, T. E. Van Deventer, M. H. Repacholi, .Workgroup Report: Base Stations And Wireless Networks . Radiofrequency (Rf) Exposures And Health Consequences", Environ. Health Persp., Vol. 115, Pp. 416-424, Mar. 2007

[66] Martin Röösli , Patrizia Frei , Evelyn Mohler \& Kerstin Hug "Systematic Review On The Health Effects Of Exposure To Radiofrequency Electromagnetic Fields From Mobile Phone Base Stations" A. Swiss Tropical And Public Health Institute And University Of Basel, Socinstrasse 59, Basel, Ch-4002, Switzerland.

[67] Sebastián Blanch, Jordi Romeu, Member, Ieee, And Angel Cardama, Member "Near Field In The Vicinity Of Wireless Base-Station Antennas: An Exposure Compliance Approach", Ieee Ieee Transactions On Antennas And Propagation, Vol. 50, No. 5, May 2002.

[68] Stratakis, Andreas I. Miaoudakis, Thomas D. Xenos, And Vassilios G. Z Dimitrios Acharopoulos "Overall Uncertainty Estimation In Multiple Narrow-Band In Situ
Electromagnetic Field Measurements". Ieee Transactions On Instrumentation And Measurement, Vol. 58, No. 8, August 2009

[69] Radio Frequency Radiation And Health: Smart Meters By Vermont Department Of Health, February 10, 2012

[70] Electromagnetic Radiation And Human Health: A Review Of Sources And Effects By Ali Zamanian And Cy Hardiman Fluor Corporation, Industrial And Infrastructure Group, July 2005.

[71] Evaluating Compliance With Fcc Guidelines For Human Exposure To Radio Frequency Electromagnetic Fields Federal Communications Commission Office Of Engineering \& Technology 1997.

[72] Basic Insights- Safety In Electric, Magnetic And Electromagnetic Fields, Narda Safety Test Solutions.

[73] "Fundamentals And Regulations Of Human Safety Concerns For Mobile Communications Devices". Dr. Duncan Fung, Consultant Hong Kong Productivity Council. Seminar Ieee Hk Emc December 2009

[74] "A Guide To Expression Of Uncertainty Of Measurements" Qa4eo - Group On Earth Observations Geo A Report

[75] Narda Safety Test Solutions Data Manual And Calibration Certificate, Narda Test Solutions Inc., Pfullingen, Germany, 2008

[76] Latin American Experts Committee Ont High Frequency Electromagnetic Fields And Human Health Scientific Review On "Non-Ionizing Electromagnetic Radiation In The Radiofrequency Spectrum And Its Effects On Human Health"

[77] Electromagnetic Fields And Public Health:Mobile Phones Fact Sheet N0 193 June 2011

[78] Terry L. Tyson "Electromagnetic Radiation: Its Possible Adverse Health Effects On Human Beings" Rsa

[79] Guide To The Expression Of Uncertainty In Measurement, Iec Standard, 1st Ed., 1995.

[80] Recommendation On Measurement Method Of Exposure To Base Stations. Tta Standard Ttas.Ko- 06.0125, 2006.

[81] Deutsches Mobilfunk Forschungsprogramm; Http://Www.Emf-Forschungsprogramm.De 